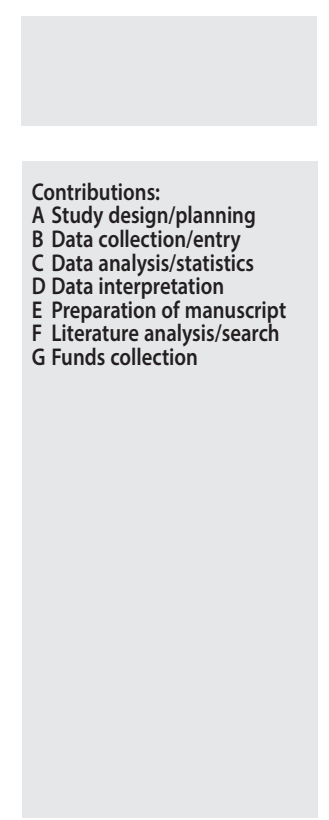

\title{
RELATION BETWEEN CERVICAL AND OCULAR VESTIBULAR EVOKED MYOGENIC POTENTIALS AND BRAINSTEM SYMPTOMS AND MRI LESIONS IN MULTIPLE SCLEROSIS PATIENTS
}

\author{
Abeir Osman Dabbous ${ }^{1, A, C-E}$, Nevin Mohieldin Shalaby ${ }^{2, A-B, D}$, \\ Alaa Eldein Ahmed Abousetta ${ }^{3, A}$, Noha Ali Hosny ${ }^{1, F}$, \\ Eman Adel Osman Soliman Fadel ${ }^{3, B-C, F}$
${ }^{1}$ Audio-Vestibular Unit, Department of Otolaryngology, Kasr-Al-Ainy Faculty of Medicine, Cairo University, Egypt
${ }^{2}$ Neurology Department, Kasr-Al-Ainy Faculty of Medicine, Cairo University, Egypt
${ }^{3}$ Audio-Vestibular Unit, Department of Otolaryngology, Faculty of Medicine, Suez-Canal University, Egypt

Corresponding author: Abeir Osman Dabbous; Audio-Vestibular Unit, Department of Otolaryngology, Kasr-Al-Ainy Faculty of Medicine, Cairo University, 12211, Giza, Cairo, Egypt; email: abeirdabbous@kasralainy.edu.eg

Abstract

Background: In multiple sclerosis (MS), even in the presence of clinical brainstem symptoms, the brainstem does not always show gross lesions on magnetic resonance imaging (MRI). However, MS may impair vestibular-evoked myogenic potential (VEMP) responses.

Material and methods: This study included 70 participants, 40 who were MS patients and 30 healthy adult volunteers as controls. All participants were subjected to history taking, otological examination, basic audiological evaluation, bedside examination of the dizzy patient, cervical VEMP (cVEMP), and ocular VEMP (oVEMP).

Results: Of the 40 MS patients, $37.5 \%$ had abnormal cVEMP and 67.5\% had abnormal oVEMP. Some $23 \%$ of the 21 MS patients without brainstem lesions on MRI had abnormal cVEMP and oVEMP, including 69\% of those who had vertigo. MS patients with brainstem lesions on MRI had significantly greater oVEMP latency than patients without similar MRI findings.

Conclusions: MS patients showed dysfunction in the vestibulo-ocular and vestibulo-spinal reflexes. This dysfunction is reflected in impaired oVEMP and cVEMP respectively despite the absence of structural brainstem abnormalities. Thus, VEMP, especially oVEMP, can be used as an early indicator of brainstem involvement in MS before radiological signs appear on MRI.

Key words: multiple sclerosis • vertigo • vestibulo-spinal reflex • vestibulo-ocular reflex • vestibular-evoked myogenic potential

\section{ZWIĄZEK MIĘDZY SZYJNYMI I OCZNYMI MIOGENNYMI PRZEDSIONKOWYMI POTENCJAŁAMI WYWOŁANYMI A OBJAWAMI Z PNIA MÓZGU I ZMIANAMI WIDOCZNYMI W MRI U PACJENTÓW ZE STWARDNIENIEM ROZSIANYM}

\section{Streszczenie}

Wprowadzenie: W stwardnieniu rozsianym (SM), nawet gdy wystepują kliniczne objawy w pniu mózgu, w badaniu rezonansu magnetycznego (MRI) nie zawsze są one widoczne w tym obszarze. SM może jednak upośledzać miogenne przedsionkowe potencjały wywołane (VEMP). Celem badania jest dokonanie funkcjonalnej oceny wyników badania cVEMP i oVEMP u pacjentów z SM i zbadanie korelacji między tymi wynikami a zmianami widocznymi w MRI i obrazem klinicznym.

Materiał i metody: W badaniu uczestniczyło 70 pacjentów: 40 z SM i grupa kontrolna złożona z 30 zdrowych dorosłych ochotników. Wszyscy uczestnicy przeszli wywiad medyczny, badanie otologiczne, podstawową ocenę audiologiczną, badanie fizykalne zawrotów głowy, badanie cVEMP i oVEMP.

Wyniki: W grupie 40 pacjentów ze stwardnieniem rozsianym 37,5\% miało nietypowe cVEMP, a 67,5\% nietypowe oVEMP. Około 23\% spośród 21 pacjentów z SM, u których w badaniu MRI nie były widoczne zmiany w obrębie pnia mózgu, miało nietypowe cVEMP i oVEMP, w tym $69 \%$ z tych, u których występowały zawroty głowy. Pacjenci z SM, u których MRI wykryło zmiany w obrębie pnia mózgu, mieli znacząco większą latencję oVEMP niż pacjenci bez takich zmian w badaniu MRI.

Wnioski: Przedsionkowo-oczne i przedsionkowo-rdzeniowe odruchy pacjentów z SM są odzwierciedlone przez upośledzone odpowiednio oVEMP i cVEMP pomimo braku strukturalnych nieprawidłowości w obrębie pnia mózgu. Stąd badania VEMP, szczególnie oVEMP mogą być stosowane jako wczesny wskaźnik uszkodzenia pnia mózgu przez SM, wcześniej niż oznaki radiologiczne będą wykrywalne w badaniu MRI.

Słowa kluczowe: stwardnienie rozsiane • zawroty głowy • odruch przedsionkowo-rdzeniowy • odruch przedsionkowo-oczny • miogenne przedsionkowe potencjały wywołane 


\section{Introduction}

Vestibular-evoked myogenic potentials (VEMPs) are now widely used to assess the function of otolithic pathways [1-3]. Cervical VEMPs (cVEMPs) are a manifestation of the vestibulo-collic reflex (VCR) and involve measuring the electromyographic (EMG) activity from tonically activated sternocleidomastoid (SCM) muscles in response to saccular stimulation [2]. VEMPs can also be recorded from the extraocular muscles using surface electrodes placed over the inferior oblique and inferior rectus muscles and are termed ocular VEMPs (oVEMPs) [4]. Contrary to cVEMPs, which are an uncrossed inhibitory vestibulo-spinal reflex (VSR), oVEMPs represent a crossed excitatory vestibuloocular reflex (VOR) [5-7].

VEMPs have generally been regarded as tests for evaluating the function of the otolithic end organs and their afferents. Thus, they have mostly been applied to disorders involving the peripheral vestibular system. However, VEMPs can also assess the function of the central vestibulo-spinal and vestibulo-ocular pathways which include the vestibular fascicle and nuclei, the medial vestibulospinal tract (VST), and the medial longitudinal fasciculus (MLF). In addition, the cerebellum may affect VEMP responses by modulating the otolithic signals. Therefore, following possible damage to the vestibular fascicles, vestibular nuclei and their efferents (as well as the cerebellum) are all potentially involved in relaying and processing vestibular signals $[8,9]$.

Multiple sclerosis (MS) is a common disease caused by an inflammatory demyelinating process in the central nervous system (CNS). MS is characterized pathologically by multifocal areas of demyelination with relative preservation of axons, resulting in much reduced conduction velocity [10]. It is clinically characterized by signs and symptoms over space and time [11]. Central vestibular lesions may impair VEMP responses along the descending (cVEMPs) and ascending (oVEMPs) tracts in the brainstem. VEMP testing is a valuable tool for detecting demyelination in the brainstem tracts of MS patients. The combined use of cVEMPs and oVEMPs might be useful for determining the site of the lesion in the brainstem $[8,12]$. Since the vestibulo-collic (vestibulo-spinal) and VOR pathways diverge beyond the nerve root entry zone and the vestibular nuclei, a central lesion causing abnormal responses of both cervical and ocular VEMPs is likely to be localized to the vestibular nerve root entry zone or the vestibular nuclei $[8,9]$.

This study aims to evaluate the findings of cervical and ocular vestibular evoked myogenic potentials (cVEMPs and oVEMPs) in multiple sclerosis patients, and to relate the cVEMP and oVEMP parameters with the lesions on MRI and clinical presentation.

\section{Material and methods}

The present study comprised 70 adult subjects of both genders, aged 20-45 years. Subjects were divided into two groups. The study group included 40 multiple sclerosis (MS) patients whose Expanded Disability Status Scale (EDSS) score was 4 or less and not in relapse, and who had dizziness with or without vertigo. They were age and sex matched to 30 healthy individuals with normal hearing as a control group. The study was approved by the Research Ethical Committee and Otolaryngology department council of Faculty of Medicine, Cairo University, registration number 1-530315. Written informed consent was given by all subjects for participation in the study, and tests were performed in the audiology unit of the ENT department, Kasr Al-Ainy hospital, Cairo university. The study took place from February 2016 to December 2018. Healthy controls were chosen from relatives of patients and working paramedical personnel. Exclusion criteria were patients with peripheral vestibular disorders including benign paroxysmal positional vertigo (BPPV), postural hypotension, general diseases causing peripheral neuropathy such as diabetes, critically ill patients, patients with impaired cognitive function and/or psychiatric disorder, patients with conductive hearing loss (conductive hearing loss impairs air conducted VEMPs), patients with peripheral extra-ocular muscles paresis or visual defect hindering the testing, patients with cervical vertebral/discogenic disorders, or if the MS patient was in relapse.

This investigation was a cross-sectional, case-control study. All participants were subjected to 1) History taking, including a full assessment of the dizziness/vertigo complaint. For the severity assessment, the Arabic translation [13] of the Dizziness Handicap Inventory questionnaire was used [14]. 2) Full general and neurological examination and EDSS scoring. MS patients in the current study were fully ambulatory without aid according to EDSS score. 3) MRI of the brain done at the radiology department, Kasr Al-Ainy hospital, Cairo university, and was read by a neurologist. 4) Otologic examination, including otoscopy and tuning fork tests. 5) Basic audiological assessment, including 5.1) Pure tone audiometry using a two channel audiometer (Itera II, Madsen Corporation, USA), calibrated according to ISO standards, using TDH 39 headphones and Radio-ear B71 bone vibrator, in a sound treated room (Amplisilence Model E), for octave frequencies $0.25-8 \mathrm{kHz}$ for air conduction and $0.5-4 \mathrm{kHz}$ for bone conduction, using pulsed stimulus. 5.1) Speech audiometry including speech reception threshold (SRT) using Arabic spondaic words [15]. Word discrimination score (WDS), using Arabic phonetically balanced words [16]. 5.3) Tympanometry and acoustic reflex threshold measurement using a Zodiac 901 (Madsen Corporation, USA), calibrated according to ISO standards, with a probe tone of $226 \mathrm{~Hz}$ and ipsilateral and contralateral elicited reflexes, using pure tones at $0.5,1,2$, and $4 \mathrm{kHz} .6$ ) Bedside examination of the dizzy patient to confirm the central origin of the complaint and to exclude peripheral vestibulopathy, including Romberg test and sharpened Romberg test. Fukuda stepping test. Gait examination and tandem walking. Test for spontaneous nystagmus to detect unidirectional horizontal nystagmus to exclude peripheral vestibulopathy, and to detect any rotatory or vertical nystagmus or direction changing nystagmus suggestive of central lesion. Head thrust test. Head shaking test to detect any post head shaking nystagmus (HSN) to exclude chronic unilateral peripheral vestibulopathy and detect any abnormal HSN result reflecting central vestibulopathy. Cover test of skew deviation to detect any vertical misalignment of the eyes. Gaze testing to detect any gaze-evoked nystagmus, suggestive of central lesion. Dix-Hallpike and Roll positioning tests to 
exclude BPPV. 7) Video-nystagmography (VNG) using VNG equipment (Micromedical Corp, USA) to exclude peripheral vestibular lesions and detect any oculomotor tests or gaze abnormalities, including spontaneous or gaze-evoked nystagmus. Oculomotor testing (saccade, smooth pursuit, and optokinetic (OPK) tests). Positional testing, to exclude BPPV. Caloric test to exclude peripheral vestibulopathy. 8) Subjective visual vertical test using VNG equipment (Difra, Belgium), to assess brainstem lesions. 9) Vestibular Evoked Myogenic Potential (VEMP) tests using NeuroAudio (Neurosoft Ltd, Russia). For cVEMP, the active electrode was placed on the middle of the sterno-cleido-mastoid (SCM) muscle, the reference electrode on the upper sternum (suprasternal notch), and the ground electrode on the forehead. Electrode impedance was kept below $5 \mathrm{k} \Omega$. Subjects were instructed to sit upright and tense the muscle by turning their chin to the contralateral shoulder. Rectified EMG was monitored during recordings to ensure low noise. Stimuli were tone bursts of $0.5 \mathrm{kHz}$ with rise and fall times of $1 \mathrm{~ms}$ and plateau of $2 \mathrm{~ms}$ presented monoaurally at $5 \mathrm{~Hz}$ through insert phones at $100 \mathrm{dBnHL}$. At least 60 sweeps were obtained using a $30-2000 \mathrm{~Hz}$ filter. The time window for analysis was $50 \mathrm{~ms}$. For oVEMP, the positive electrode was placed on the orbital margin below the center of the eye and the reference electrode placed 15-30 mm below the positive electrode, on the cheek, with the ground electrode on the forehead. Subjects were instructed to sit upright, relax their facial muscles, and look up with their eyes without moving their head. At least 200 sweeps were made with a $1-1000 \mathrm{~Hz}$ filter. Other conditions were the same as with cVEMP. VEMP responses were judged as either present or absent according to the presence or absence of a biphasic response. Parameters measured were latency in $\mathrm{ms}$ and amplitude in $\mu \mathrm{V}$. For cVEMP, measurements were made of P13 latency, N23 latency, and P13N23 peak-to-peak amplitude, and the inter-aural amplitude difference (IAAD) ratio. For oVEMP, measures were N10 latency, P15 latency, N10-P15 peak-to-peak amplitude, and IAAD. For a reliable interpretation of left-right difference in VEMP, the amount of the muscle contraction has to be considered. Therefore, we need to ensure that any difference in amplitude between the right and left VEMPs on a patient is due to vestibular abnormality, not due to individual differences of tonic muscle activity, fatigue, or improper position. In cVEMP and oVEMP, we used rectified amplitude, a method that simultaneously measures the muscle contraction power during VEMP recordings. We also used rectification to normalize the electromyograph (EMG) based on pre-stimulus EMG activity. The baselinenormalized value of amplitude (averaged EMG) is calculated by dividing the absolute peak-to-peak amplitude with the mean value of rectified activity of muscle in the period prior to the stimulus.

Data collected from the control group and the cases was coded, entered, and analyzed using Microsoft Excel 2010 software and then imported into SPSS (Statistical Package for Social Science) version 19.0 for analysis. Description of variables was presented as follows. Quantitative variables were in the form of mean and standard deviation (SD); qualitative variables were in the form of numbers and percent. According to the type of data, a MannWhitney $U$-test and Chi-square test with least significance difference were performed to test for significant differences.
Pearson's correlation test was used to determine correlations between individual results. Differences were considered statistically significant at $p<0.05$.

\section{Results}

The study included 40 patients with MS, 29 (72.5\%) females, and $11(27.5 \%)$ males with a mean age of $29.9 \pm 7.2$, ranging from 23.0 to 45.0 years. The control group included 30 healthy participants, 15 (50\%) female and 15 (50\%) males, with a mean age of $29.8 \pm 5.4$, ranging from 24.0 to 44.0 years. Groups were matched regarding age and gender $(p=0.945 ; p=0.080)$ respectively. The mean MS duration was $5.3 \pm 3$ years, ranging from 1 to 15 years; 39 (97.5\%) of patients were under treatment. The mean EDSS score was $1.9 \pm 2$, ranging from 0 to 4 with a median of 1.6.

Regarding the clinical symptoms: $5 / 40$ (12.5\%) had tinnitus, 40 (100\%) had dizziness, 22 (55\%) had vertigo, and $8(20 \%)$ had dysarthria. MS patients with brainstem symptoms only: $5 / 40$ (12.5\%); those with cerebellar symptoms only: $14 / 40$ (35\%); those with combined cerebellar and brainstem symptoms: 15/40 (37.5\%); and those without any cerebellar or brainstem symptoms: 6/40 (15\%).

Regarding the severity of vertigo detected by the DHI, the majority of the MS group had a moderate degree of handicap (Table 1). Regarding MRI findings: MS patients with brainstem only MRI lesions were 10 (25\%), those with cerebellar only MRI lesions were 9 (22.5\%), those with brainstem and cerebellar lesions were 9 (22.5\%), while other MRI lesions (juxtacortical, periventricular, and pericallosal) were found in $12(30 \%)$. Regarding PTA in MS patients: 37 (92.5\%) and 36 (90\%) had normal hearing, while $3(7.5 \%)$ and $4(10 \%)$ had high frequency sensorineural hearing loss at 4 and $8 \mathrm{kHz}$ in the right and left ears respectively.

In MS patients the mean clockwise subjective visual vertical (CW-SVV) was $0.5 \pm 1$, ranging from -3.5 to 3.1 ; the mean counterclockwise (CCW-SVV) was $0.53 \pm 1$, ranging from -3 to 3.4 ; the mean CW and CCW Average -SVV was $1.01 \pm 0.8$, ranging from 0.15 to 3.45 . In the controls, the mean CW-SVV was $0.7 \pm 0.3$, ranging from 0 to 1.4 ;

Table 1. Severity of vertigo in MS patients $(n=40)$ measured by the Dizziness Handicap Inventory total score and its subscale scores. $\mathrm{F}=$ functional; $\mathrm{P}=$ physical; $\mathrm{E}=$ emotional

\begin{tabular}{lcc}
\hline \multirow{2}{*}{ F score } & mean \pm SD & $20 \pm 3$ \\
\cline { 2 - 3 } & min - max & $14-26$ \\
\hline \multirow{2}{*}{ P score } & mean \pm SD & $7.1 \pm 1.8$ \\
\cline { 2 - 3 } E score & min - max & $4-12$ \\
\hline \multirow{3}{*}{ Total score } & mean \pm SD & $16.6 \pm 3.1$ \\
\cline { 2 - 3 } & mean \pm SD & $12-24$ \\
\hline \multirow{2}{*}{$\begin{array}{l}\text { Handicap degree } \\
\text { No. (\%) }\end{array}$} & min - max & $43.7 \pm 6.8$ \\
\cline { 2 - 3 } & mild & $32-60$ \\
\cline { 2 - 3 } & moderate & $31(12.5 \%)$ \\
\hline
\end{tabular}


the mean CCW-SVV was $0.82 \pm 0.3$, ranging from 0.3 to 1.4; the mean CW and CCW Average -SVV was $0.78 \pm 0.3$, ranging from 0.35 to 1.3 . There were no statistically significant differences between MS patients and the control groups regarding SVV $(p>0.05)$. However, only $4 / 40$ patients $(10 \%)$ showed an abnormal SVV result.

Occulographic abnormalities were found in all MS patients: abnormal saccades in 35 (87.5\%), abnormal OPK test results in $31(77.5 \%)$, abnormal smooth pursuit in 26 (65\%). Gazeevoked nystagmus were found in $6(15 \%)$ of the MS patients, central spontaneous nystagmus in $7(17.5 \%)$, and test of skew was positive in $3(7.5 \%)$.

In MS patients, cVEMP was lost unilaterally in 2 patients, and oVEMP was lost unilaterally in 4 patients and lost bilaterally in 1 patient.

There were statistically significant $(p<0.05)$ delayed Lt cVEMP P13 latency, and Lt cVEMP N23 latency, in the MS patients compared to the normal controls. However, there was no statistically significant difference between both groups regarding amplitude asymmetry (Table 2 ). Four cases $(10 \%)$ showed asymmetrical cVEMP (2 of them had 100\% asymmetry: unilaterally lost cVEMP, not included in Table 2), and 36/40 (90\%) patients showed symmetrical cVEMP. There was a statistically significant $(p<0.05)$ delayed Rt oVEMP N1 and P1 latencies in the MS patients compared to the controls. MS patients showed statistically significant less rectified oVEMP amplitude on both sides (Table 3 ).

According to our normative values, cVEMP interaural amplitude difference ratio percent (IAAD $\%)>36.55 \%$ and oVEMP IAAD $\%>36.1 \%$ was considered abnormal, reflecting amplitude asymmetry. cVEMP abnormalities in MS patients: 2 (13.3\%) had amplitude asymmetry, 11 (73.3\%) had latency delay, and 2 (13.3\%) had both amplitude asymmetry and latency delay. oVEMP abnormalities in MS patients: 5 (18.5\%) had amplitude asymmetry, 14 (51.9\%) had latency delay, and 7 (25.9\%) had both amplitude asymmetry and latency delay, and 1 (3.7\%) had bilateral lost oVEMP.

Table 4 shows the distribution of latency and amplitude asymmetry abnormalities, and final cVEMP and oVEMP results, in MS patients. The final VEMP result was considered normal if both the latency and amplitude were normal and considered abnormal if either the latency or the amplitude or both were abnormal. The majority of MS subjects showed abnormal oVEMP, while the majority showed normal cVEMPs. Table 5 shows the relation between cVEMP and oVEMP abnormality distribution (including latency delay, asymmetry or loss) in MS patients. The majority of the abnormal cVEMPs showed abnormal oVEMPs, and the majority of the normal oVEMPs showed normal cVEMPs, and this abnormality distribution was statistically significant (Table 5).

There were statistically significant less cVEMP amplitude and rectified amplitude asymmetry in MS patients with vertigo than patients without vertigo, but of borderline significance, even though only $9.1 \%$ showed asymmetry and the asymmetry distribution was not statistically significant between both groups. There were statistically significant delayed Lt cVEMP P13 and Lt cVEMP N23 latencies in MS patients with vertigo compared to the control group.

There was statistically significant more oVEMP amplitude asymmetry in MS patients with vertigo than in patients without vertigo, but still the asymmetry distribution was not statistically significant between both groups. There were statistically significant delayed Rt oVEMP N1, Rt oVEMP P1 latencies, less rectified amplitude in both ears, and more amplitude asymmetry in MS patients with vertigo compared to their controls.

There were no statistically significant differences between MS patients with or without brainstem symptoms or between MS patients with or without cerebellar symptoms regarding any of the studied cVEMP and oVEMP parameters.

Table 2. Comparison of cVEMP parameters between MS patients $(n=40)$ and normal controls $(n=30)$

\begin{tabular}{|c|c|c|c|c|c|c|c|c|c|c|}
\hline \multirow{2}{*}{ cVEMP } & & \multicolumn{4}{|c|}{ MS cases $(n=40)$} & \multicolumn{4}{|c|}{ Controls $(n=30)$} & \multirow{2}{*}{$p$-value } \\
\hline & & Mean & SD & Min & Max & Mean & SD & Min & Max & \\
\hline \multirow{4}{*}{ Rt } & P13 (in ms) & 15.33 & 3.06 & 12.3 & 25.8 & 14.22 & 1.25 & 12.0 & 16.5 & 0.067 \\
\hline & N23 (in ms) & 22.63 & 3.26 & 17.7 & 34.1 & 22.18 & 2.25 & 16.5 & 27.5 & 0.532 \\
\hline & $\begin{array}{l}\text { P13-N23 amp } \\
\text { (in } \mu \mathrm{V})\end{array}$ & 43.53 & 14.8 & 14.1 & 82.1 & 44.41 & 19.36 & 10.7 & 89.7 & 0.833 \\
\hline & $\begin{array}{l}\text { Rectified P13-N23 amp } \\
\text { (in } \mu \mathrm{V})\end{array}$ & 1.04 & 0.54 & 0.2 & 2.9 & 1.05 & 0.57 & 0.2 & 2.7 & 0.918 \\
\hline \multirow{4}{*}{ Lt } & P13 (in ms) & 15.54 & 2.81 & 11.6 & 27.6 & 14.07 & 0.95 & 12.3 & 16.1 & $0.008^{*}$ \\
\hline & N23 (in ms) & 23.47 & 3.65 & 19.2 & 36.9 & 21.92 & 1.91 & 17.3 & 26.2 & $0.038^{*}$ \\
\hline & $\begin{array}{l}\text { P13-N23 amp } \\
\text { (in } \mu \mathrm{V})\end{array}$ & 41.81 & 12.75 & 16.6 & 77.6 & 43.97 & 22.03 & 8.1 & 92.1 & 0.607 \\
\hline & $\begin{array}{l}\text { Rectified P13-N23 amp } \\
\text { (in } \mu \mathrm{V})\end{array}$ & 1.05 & 0.51 & 0.4 & 3.1 & 1.09 & 0.64 & 0.2 & 3.2 & 0.771 \\
\hline \multicolumn{2}{|l|}{ IAAD** } & 15.26 & 11.73 & 1.4 & 49 & 16.53 & 10.01 & 0.2 & 30.4 & 0.639 \\
\hline \multicolumn{2}{|c|}{ Rectified IAAD** } & 16.94 & 13.47 & 0 & 59.8 & 16.22 & 10.52 & 0.0 & 35.0 & 0.812 \\
\hline
\end{tabular}

${ }^{*} p$-value is statistically significant

*** Max IAAD did not include $100 \%$ asymmetry value due to unilaterally lost CVEMP in 2 patients 
Table 3. Comparison of oVEMP parameters between MS patients $(n=40)$ and normal controls $(n=30)$

\begin{tabular}{|c|c|c|c|c|c|c|c|c|c|c|}
\hline & \multirow{2}{*}{ oVEMP } & \multicolumn{4}{|c|}{ MS cases $(n=40)$} & \multicolumn{4}{|c|}{ Controls $(n=30)$} & \multirow{2}{*}{$p$-value } \\
\hline & & Mean & SD & Min & Max & Mean & SD & Min & Max & \\
\hline \multirow{4}{*}{ Rt } & $\mathrm{N} 1$ (in ms) & 11.69 & 1.47 & 7.7 & 16.1 & 10.61 & 0.67 & 9.4 & 12.0 & $0.002^{*}$ \\
\hline & $\mathrm{P} 1$ (in ms) & 16.8 & 2.56 & 12.5 & 23.1 & 15.53 & 0.88 & 12.5 & 17.5 & $0.012^{*}$ \\
\hline & $\begin{array}{l}\text { N1-P1 amp } \\
\text { (in } \mu \mathrm{V})\end{array}$ & 5.01 & 2.54 & 0.1 & 16.9 & 4.05 & 3.61 & 0.6 & 17.2 & 0.36 \\
\hline & Rectified N1-P1 amp (in $\mu \mathrm{V}$ ) & 0.19 & 0.18 & 0.1 & 0.9 & 0.48 & 0.36 & 0.1 & 1.2 & $<0.001^{*}$ \\
\hline \multirow{4}{*}{ Lt } & $\mathrm{N} 1$ (in ms) & 11.43 & 1.89 & 8.3 & 19.1 & 10.64 & 0.74 & 9 & 12.4 & 0.052 \\
\hline & $\mathrm{P} 1$ (in $\mathrm{ms}$ ) & 15.89 & 2.02 & 12.5 & 24.5 & 15.3 & 2.1 & 5.7 & 17.7 & 0.282 \\
\hline & $\begin{array}{l}\text { N1-P1 amp } \\
\text { (in } \mu \mathrm{V})\end{array}$ & 5.19 & 2.29 & 0.1 & 28.6 & 4.4 & 3.42 & 0.5 & 13.4 & 0.467 \\
\hline & Rectified N1-P1 amp (in $\mu \mathrm{V}$ ) & 0.24 & 0.18 & 0.1 & 0.9 & 0.41 & 0.25 & 0.1 & 0.9 & $0.006^{*}$ \\
\hline $\mathrm{IAAD}^{* *}$ & & 21.78 & 13.96 & 0.4 & 60.7 & 17.59 & 9.25 & 0.2 & 30.4 & 0.231 \\
\hline \multicolumn{2}{|c|}{ Rectified IAAD** } & 21.85 & 25.1 & 0 & 60 & 16.79 & 12.92 & 0 & 42.8 & 0.321 \\
\hline
\end{tabular}

${ }^{*} p$-value is statistically significant

**Max IAAD did not include $100 \%$ asymmetry value due to unilaterally lost oVEMP in 4 patients

Table 4. Distribution of latency and amplitude asymmetry abnormalities in MS patients. Final cVEMP and oVEMP results, including latency, asymmetry, or loss

\begin{tabular}{|c|c|c|c|}
\hline \multirow{4}{*}{ cVEMP latency result } & \multirow{2}{*}{ Delay } & No. & 13 \\
\hline & & $\%$ & $32.5 \%$ \\
\hline & \multirow{2}{*}{ No delay } & No. & 27 \\
\hline & & $\%$ & $67.5 \%$ \\
\hline \multirow{4}{*}{ cVEMP amplitude symmetry } & \multirow{2}{*}{ Asymmetrical } & No. & 4 \\
\hline & & $\%$ & $10.0 \%$ \\
\hline & \multirow{2}{*}{ Symmetrical } & No. & 36 \\
\hline & & $\%$ & $90.0 \%$ \\
\hline \multirow{6}{*}{ oVEMP latency result** } & \multirow{2}{*}{ Delay } & No. & 21 \\
\hline & & $\%$ & $52.5 \%$ \\
\hline & \multirow{2}{*}{ No delay } & No. & 18 \\
\hline & & $\%$ & $45 \%$ \\
\hline & \multirow{2}{*}{ Bilaterally lost } & No. & 1 \\
\hline & & $\%$ & $2.5 \%$ \\
\hline \multirow{6}{*}{ oVEMP amplitude symmetry* } & \multirow{2}{*}{ Asymmetrical } & No. & 12 \\
\hline & & $\%$ & $30 \%$ \\
\hline & \multirow{2}{*}{ Symmetrical } & No. & 27 \\
\hline & & $\%$ & $67.5 \%$ \\
\hline & \multirow{2}{*}{ Bilaterally lost } & No. & 1 \\
\hline & & $\%$ & $2.5 \%$ \\
\hline \multirow{4}{*}{ Final cVEMP result } & \multirow{2}{*}{ Abnormal } & No. & 15 \\
\hline & & $\%$ & $37.5 \%$ \\
\hline & \multirow{2}{*}{ Normal } & No. & 25 \\
\hline & & $\%$ & $62.5 \%$ \\
\hline \multirow{4}{*}{ Final oVEMP result } & \multirow{2}{*}{ Abnormal } & No. & 27 \\
\hline & & $\%$ & $67.5 \%$ \\
\hline & \multirow{2}{*}{ Normal } & No. & 13 \\
\hline & & $\%$ & $32.5 \%$ \\
\hline
\end{tabular}

*N.B. Asymmetrical cVEMP and oVEMP includes patients with total unilateral loss (100\% asymmetry) 
Table 5. Relation between CVEMP and oVEMP results (including latency, asymmetry, or loss) in MS patients

\begin{tabular}{lcccc}
\hline & & \multicolumn{2}{c}{ Final cVEMP result } & \\
\cline { 3 - 5 } & & Abnormal & Normal & Total \\
\hline \multirow{2}{*}{ Final oVEMP result } & Abnormal & $14(93.33 \%)$ & $13(52 \%)$ & $27(67.5 \%)$ \\
\hline & Normal & $1(6.67 \%)$ & $12(48 \%)$ & $13(32.5 \%)$ \\
\hline & Total & $15(100 \%)$ & $25(100 \%)$ & $40(100 \%)$ \\
\hline
\end{tabular}

$x^{2}=7.301, p=0.013^{*}\left({ }^{*} p\right.$-value is statistically significant)

Table 6. Correlation between combined VEMP results and MRI findings in MS patients $(n=40)$

\begin{tabular}{|c|c|c|c|c|c|c|c|}
\hline & & & \multicolumn{4}{|c|}{ Lesions on MRI } & \multirow[b]{2}{*}{ Total } \\
\hline & & & B & C & B, C & other & \\
\hline \multirow{8}{*}{$\begin{array}{l}\text { Combined } \\
\text { VEMP results }\end{array}$} & \multirow{2}{*}{ Both normal } & No. & 1 & 5 & 2 & 4 & 12 \\
\hline & & $\%$ & $10 \%$ & $55.6 \%$ & $22.2 \%$ & $33.3 \%$ & $30.0 \%$ \\
\hline & \multirow{2}{*}{ Both VEMPs abnormal } & No. & 6 & 2 & 3 & 3 & 14 \\
\hline & & $\%$ & $60 \%$ & $22.2 \%$ & $33.3 \%$ & $25 \%$ & $35.0 \%$ \\
\hline & \multirow{2}{*}{ cVEMP abnormal } & No. & 0 & 0 & 1 & 0 & 1 \\
\hline & & $\%$ & $0 \%$ & $0 \%$ & $11.1 \%$ & $0 \%$ & $2.5 \%$ \\
\hline & \multirow{2}{*}{ oVEMP abnormal } & No. & 3 & 2 & 3 & 5 & 13 \\
\hline & & $\%$ & $30 \%$ & $22.2 \%$ & $33.3 \%$ & $41.7 \%$ & $32.5 \%$ \\
\hline \multirow{2}{*}{ Total } & & No. & 10 & 9 & 9 & 12 & 40 \\
\hline & & $\%$ & $100 \%$ & $100 \%$ & $100 \%$ & $100 \%$ & $100 \%$ \\
\hline
\end{tabular}

$X^{2}=10.142 ; p=0.339$

$\mathrm{B}=$ brainstem; $\mathrm{C}=$ cerebellum

There were no statistically significant differences between MS patients with combined cerebellar and brainstem symptoms and those without any cerebellar or brainstem symptoms regarding any of the studied cVEMP and oVEMP parameters, although the majority of those with combined cerebellar and brainstem symptoms (60\%) had abnormal cVEMP, and the majority of those without any cerebellar or brainstem symptoms (66.7\%) had normal cVEMP, and although those with combined cerebellar and brainstem symptoms had a higher percentage (86.7\%) of abnormal oVEMP than those without any cerebellar or brainstem symptoms (66.7\%).

MS patients showed different lesions on MRI: juxtacortical in 26/40 (65\%); periventricular in 38/40 (95\%); brainstem in $19 / 40$ (47.5\%); pericallosal in 14/40 (35\%); cerebellar in 19/40 (47.5\%). Numbers are not mutually exclusive as a patient could have more than one site of lesion. Thus, 19 MS patients had brainstem lesions on MRI while $21 \mathrm{did}$ not. Brainstem lesion alone was found in 10/40 (25\%), cerebellar lesion alone was found in 9/40 (22.5\%), brainstem combined with cerebellar lesions were found in 9/40 (22.5\%), and 12/40 (30\%) showed other MRI lesion sites. There were no statistically significant differences of cVEMP or oVEMP results between MS patients with or without brainstem lesions on MRI, except that patients with brainstem lesions on MRI had statistically significant greater percentage of oVEMP latency delay (68.4\%) than patients without brainstem lesions $(38.1 \%)$. Although patients with brainstem lesions on MRI had statistically non-significant greater percentage of cVEMP latency delay (47\%) than patients without brainstem lesions (19\%), those without brainstem lesions on MRI still showed delayed cVEMP latency.

There was no statistically significant difference on further analyses of the distribution of the side of latency delay (whether right or left or bilateral) in either the cVEMP or the oVEMP and the presence or absence of brainstem involvement on MRI $(p>0.05)$.

There were no statistically significant differences among MS patients with different lesions on MRI regarding cVEMP or oVEMP values (Kruskal-Wallis test for association between MRI finding and oVEMP), except for a statistically significant delayed Rt oVEMP P1 latency in the patients with brainstem lesions on MRI and those with cerebellar lesions on MRI, and between patients with brainstem lesions on MRI and those with "other" lesions on MRI.

Although $60 \%$ of MS patients with brainstem lesions on MRI had both types of VEMP abnormal, there were no statistically significant differences regarding the distribution $\left(\chi^{2}\right)$ of combined VEMP results among MS patients with different lesions on MRI (Table 6).

Of the 22 MS patients with vertigo: none had abnormal cVEMP only, while 9/22 (41\%) had abnormal oVEMP only, and 7/22 (32\%) had both abnormal cVEMP and abnormal oVEMP, and 6 (27\%) had both normal cVEMP and normal oVEMP (Table 6). That is, 16/22 (73\%) had an abnormal VEMP (cVEMP, oVEMP, or both). 
Table 7. Distribution of combined VEMP results with presence or absence of vertigo, brainstem symptoms, and brainstem lesions on MRI in MS patients $(n=40)$

\begin{tabular}{|c|c|c|c|c|c|c|c|c|}
\hline & & & \multicolumn{4}{|c|}{ Combined VEMP results } & \multirow[b]{2}{*}{ Total } & \multirow[b]{2}{*}{$p$-value } \\
\hline & & & $\begin{array}{c}\text { Both VEMPs } \\
\text { normal } \\
(n=12)\end{array}$ & $\begin{array}{l}\text { Both VEMPs } \\
\text { abnormal } \\
(n=14)\end{array}$ & $\begin{array}{l}\text { cVEMP only } \\
\text { abnormal } \\
(n=1)\end{array}$ & $\begin{array}{l}\text { oVEMP only } \\
\text { abnormal } \\
(n=13)\end{array}$ & & \\
\hline \multirow{4}{*}{$\begin{array}{l}\text { Brainstem } \\
\text { symptoms }\end{array}$} & \multirow{2}{*}{ NO } & No. & 9 & 5 & 0 & 6 & 20 & \multirow{4}{*}{0.156} \\
\hline & & $\%$ & 22.5 & 12.5 & 0 & 15.0 & $50 \%$ & \\
\hline & \multirow{2}{*}{ YES } & No. & 3 & 9 & 1 & 7 & 20 & \\
\hline & & $\%$ & 7.5 & 22.5 & 2.5 & 17.5 & $50 \%$ & \\
\hline \multirow{4}{*}{$\begin{array}{l}\text { Brainstem } \\
\text { and } \\
\text { cerebellar } \\
\text { symptoms }\end{array}$} & \multirow{2}{*}{ NO } & No. & 10 & 5 & 0 & 8 & 23 & \multirow{4}{*}{0.059} \\
\hline & & $\%$ & 25 & 12.5 & 0 & 20 & $57.5 \%$ & \\
\hline & \multirow{2}{*}{ YES } & No. & 2 & 9 & 1 & 5 & 17 & \\
\hline & & $\%$ & 5 & 22.5 & 2.5 & 12.5 & $42.5 \%$ & \\
\hline \multirow{4}{*}{$\begin{array}{l}\text { Cerebellar } \\
\text { symptoms }\end{array}$} & \multirow{2}{*}{ NO } & No. & 4 & 3 & 0 & 4 & 11 & \multirow{4}{*}{0.822} \\
\hline & & $\%$ & 10 & 7.5 & 0 & 10 & $27.5 \%$ & \\
\hline & \multirow{2}{*}{ YES } & No. & 8 & 11 & 1 & 9 & 29 & \\
\hline & & $\%$ & 20 & 27.5 & 2,5 & 22.5 & $70 \%$ & \\
\hline \multirow{4}{*}{$\begin{array}{l}\text { Brainstem } \\
\text { lesions on } \\
\text { MRI }\end{array}$} & \multirow{2}{*}{ NO } & No. & 9 & 5 & 0 & 7 & 21 & \multirow{4}{*}{0.162} \\
\hline & & $\%$ & 22.5 & 12.5 & 0 & 17.5 & $52.5 \%$ & \\
\hline & \multirow{2}{*}{ YES } & No. & 3 & 9 & 1 & 6 & 19 & \\
\hline & & $\%$ & 7.5 & 22.5 & 2.5 & 15 & $47.5 \%$ & \\
\hline \multirow{4}{*}{ Vertigo } & \multirow{2}{*}{ NO } & No. & 6 & 7 & 1 & 4 & 18 & \multirow{4}{*}{0.467} \\
\hline & & $\%$ & 15 & 17.5 & 2.5 & 10 & $45 \%$ & \\
\hline & \multirow{2}{*}{ YES } & No. & 6 & 7 & 0 & 9 & 22 & \\
\hline & & $\%$ & 15 & 17.5 & 0 & 22.5 & $55 \%$ & \\
\hline
\end{tabular}

Of the 21 MS patients with no brainstem lesions on MRI, $7 / 21$ (30\%) had abnormal oVEMP only, and 5/21 (24\%) had both abnormal cVEMP and abnormal oVEMP (Table 6). That is, 12/21 (57\%) had an abnormal VEMP (cVEMP, oVEMP or both). Of the $28 \mathrm{MS}$ patients (70\%) having an abnormal VEMP (cVEMP, oVEMP or both): 12/28 (43\%) had a normal MRI (Table 7). However, in MS patients there was no statistically significant difference in the distribution of cVEMP and oVEMP abnormality with the presence or absence of vertigo, other brainstem symptoms, or brainstem lesions on MRI.

There were no statistically significant differences between MS patients with vertigo but without brainstem lesions on MRI (13 cases) and the controls regarding cVEMP and oVEMP findings, except for cVEMP amplitude asymmetry, although this was within the normal range. Furthermore $12 / 13$ (92\%) had symmetrical cVEMP. Only one had asymmetrical cVEMP and 2 had delayed latency (i.e., $3 / 13$ (23\%) had abnormal cVEMP) (Figure 1).

Compared to the controls, there were statistically significant delayed Rt N1 and P1 latencies and greater Rt oVEMP rectified amplitude asymmetry in MS patients with vertigo but without brainstem lesions on MRI $(n=13)$. oVEMP was abnormal in 9/13 (69\%) including: latency delay in $5 / 13(39 \%)$, asymmetry in $2 / 13(15 \%)$, asymmetry and latency delay in 2/13 (15\%) (Figure 1).

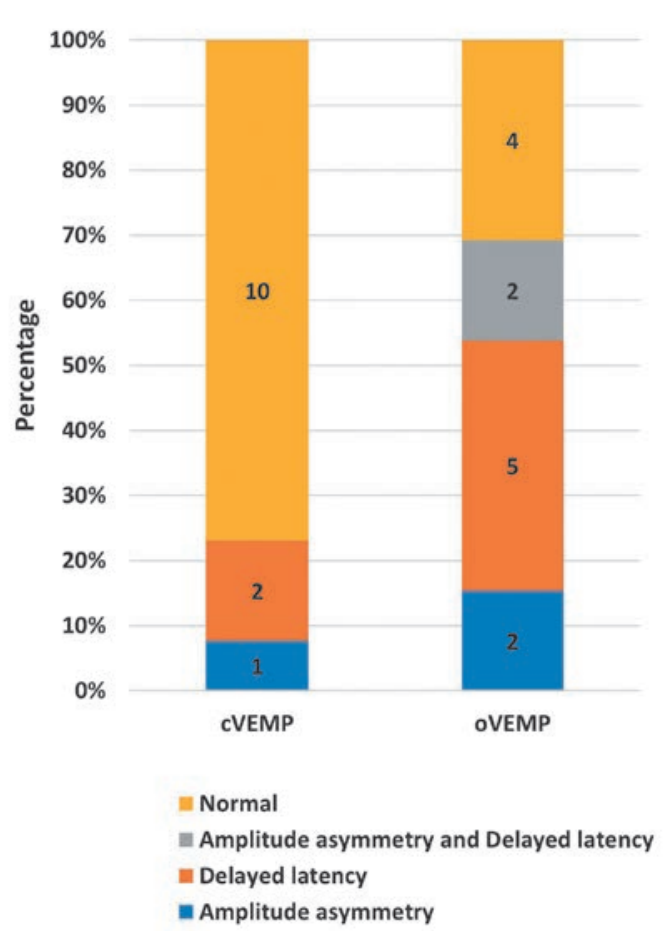

Figure 1. CVEMP and oVEMP findings in MS patients with vertigo but without brainstem lesions on MRI 
Table 8. Correlation between cVEMP and oVEMP findings and Dizziness Handicap Inventory in MS group $(n=40)$

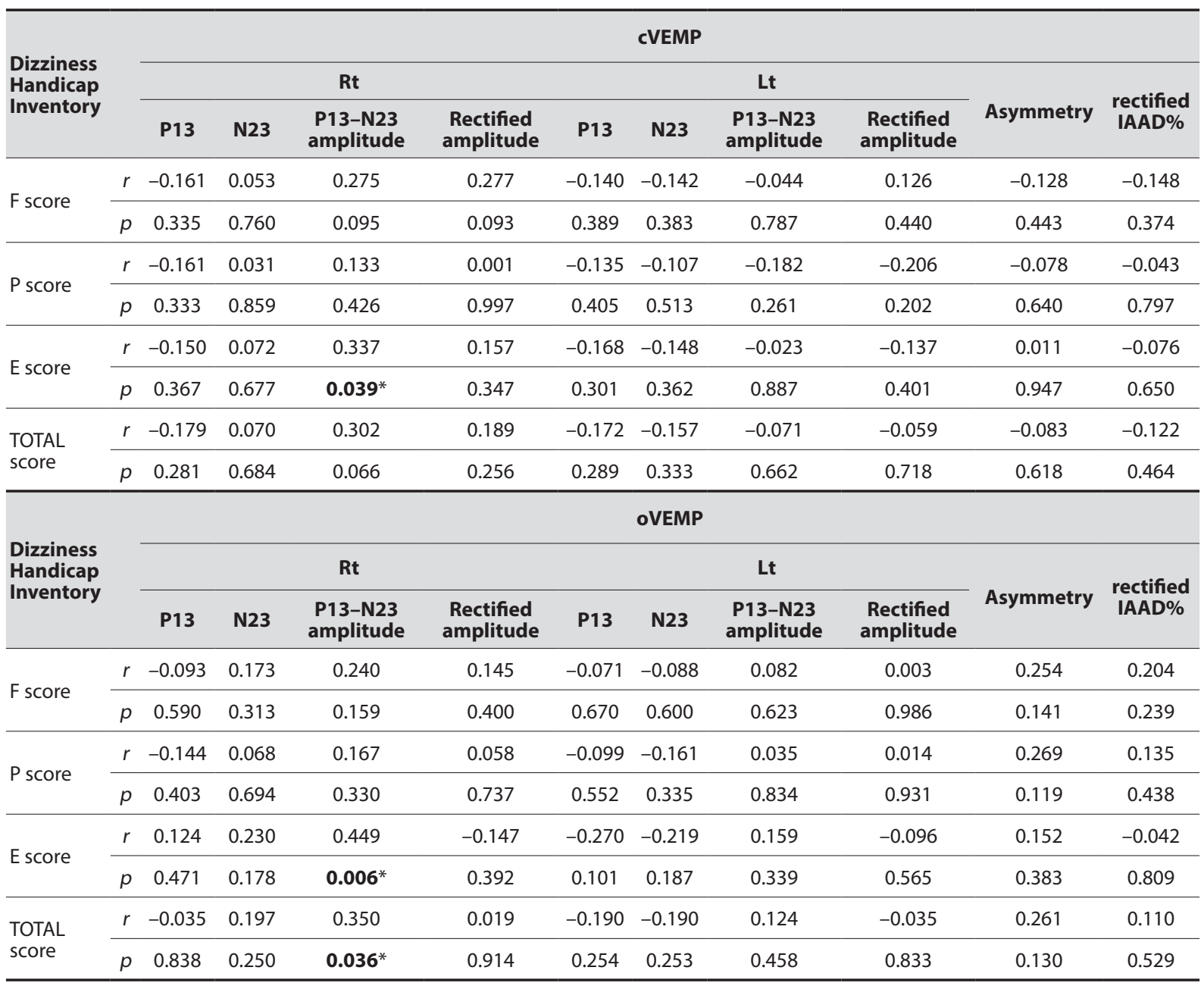

${ }^{*} p$-value is statistically significant

In the present study neither the age of the MS patient, the duration of MS, or the EDSS scores of MS patients were correlated to either DHI scores, SVV, cVEMP, or oVEMP results. Assessed by the total DHI score, the majority of the MS group - 31/40 patients $(77.5 \%)$ - had a moderate degree of handicap. In MS patients, as the total DHI score increased, the Rt N1-P1 oVEMP amplitude increased, and as the emotional DHI score increased, the Rt P13-N23 cVEMP amplitude and Rt N1-P1 oVEMP amplitude increased, but it was a weak positive correlation) (Table 8).

\section{Discussion}

\section{Comparison of cVEMP and oVEMP in MS and controls}

In this study cVEMP abnormality was found in 15/40 MS patients (37.5\%), mainly in the form of a latency delay in $11 / 15$ (73\%). Only $2 / 15$ (13\%) had amplitude asymmetry, and $2 / 15(13 \%)$ had both cVEMP latency delay and amplitude asymmetry. This reflected a lesion in the vestibulocollic reflex, a part of the VSR ending in the neck, secondary to demylelination.
In cVEMP testing of 42 ears of 21 relapsing-remitting multiple sclerosis (RRMS) patients, Tutar et al. [17] found that the mean P1 and N1 latencies of the left ears of RRMS patients were significantly higher compared to the controls. There was no significant difference between patients and controls in terms of the P1-N1 interval or mean amplitude of the left ear $(p>0.05)$. The P1 and N1 latencies and the mean P1-N1 interval of the right ears of RRMS patients were significantly higher than the controls. The P1 and N1 latencies were prolonged in 13 (42\%) of 42 RRMS ears and 27 ears $(64 \%)$, respectively.

Gazioglu and Boz [18] found that cVEMPs were detectable from both sides in all patients. oVEMPs were recordable from both sides in 56 patients, from one side in 3 patients and were absent bilaterally in 3 patients (which is near to our results). oVEMP mean $\mathrm{N} 1$ and $\mathrm{P} 1$ latencies and cVEMP mean P13 latency were significantly prolonged in MS patients $(p<0.01)$. But there were no significant differences in cVEMP mean N23 latencies between MS patients and control subjects. But there were no significant differences observed in amplitude asymmetry ratios or interpeak latency differences of either oVEMP or cVEMP, which agree with our results. 
Güven et al. [19] studied cVEMP in MS patients and found that $\mathrm{P} 1-\mathrm{N} 1$ and $\mathrm{N} 2-\mathrm{P} 2$ waves were absent more frequently in the MS patients than in controls. The mean $\mathrm{P} 1-\mathrm{N} 1$ amplitude was significantly lower in the MS group than in the control groups. There were no significant differences between the MS and control groups in mean P1, N1, N2, or P2 latency or N2-P2 amplitude. However, our study does not agree with theirs.

Koura and Hussein [20] found that $60 \%$ of patients with MS were found to have absent VEMP (P13-N23) on both the right and left sides, which is a higher percentage than ours. Patients with preserved VEMP were found to have significantly delayed latency (P13-N23) in both right and left sides than controls. The delayed cVEMP P1 latency agrees with the present study results.

In the current study abnormal oVEMP results were found in $27 / 40(67.5 \%)$, mainly in the form of latency delay in $14 / 40(52 \%)$ of MS patients, with 5/40 (18.5\%) of MS patients with oVEMP amplitude asymmetry, and 7/40 (26\%) with both oVEMP latency delay and amplitude asymmetry and bilaterally lost oVEMP in 1 patient. This reflected VOR pathology secondary to demyelination.

Somasundaram et al. [21] found that the evoked potential latencies (P13 of cVEMP followed by N10 oVEMP) had the highest predictive accuracy in predicting a future fall when compared to clinical measures. So, these parameters can be routinely tested in all MS patients, with $\mathrm{P} 13$ being the most reliable parameter - in agreement with the present study results.

For oVEMP testing, Tutar et al. [17] found that 8 RRMS patients $(19 \%)$ had no response in the oVEMP test of the right ear $(n=4)$ and left ear $(n=4)$. There was no significant difference in $\mathrm{P} 1$ or $\mathrm{N} 1$ latencies or the P1-N1 inter$\mathrm{val}$, amplitude of right ears, or amplitude asymmetry ratio between the patients and controls ( $p>0.05$ for all). In RRMS ears, the P1 and N1 latencies were prolonged in 26 (62\%) and 27 ears (64\%), respectively.

Central vestibular lesions may impair the VEMP responses along the descending tracts (cVEMPs) and ascending tracts (oVEMPs) in the brainstem. Since the vestibulo-collic (vestibulo-spinal) and VOR pathways diverge beyond the nerve root entry zone and the vestibular nuclei, both cVEMPs and oVEMPs would, when combined, provide valuable information in localizing the central lesions. Thus, a central lesion causing abnormal responses for both cVEMPs and oVEMPs is likely to be localized to the vestibular nerve root entry zone or the vestibular nuclei $[22,23]$.

\section{Correlation of cVEMP and oVEMP findings with clinical symptoms}

MS patients with vertigo in the current study showed statistically significant delayed cVEMPs and oVEMPs compared to those without vertigo, suggesting that cVEMP and oVEMP can show subclinical brainstem involvement in MS, despite the absence of obvious brainstem involvement.

In the current study, of the MS patients having vertigo, none had abnormal cVEMP only, while 9/22 (41\%) had abnormal oVEMP only, and 7/22 (32\%) had abnormal both cVEMP and oVEMP, and 6 (27\%) had normal both cVEMP and oVEMP. So, the ascending brainstem pathway represented by the VOR was more affected than the descending brainstem pathway represented by the vestibulo-collic reflex. About two-thirds of all abnormal VEMPs had a normal MRI, highlighting the importance of VEMP testing, especially the oVEMP as an early indicator before radiological signs of brainstem involvement begin to appear.

In accordance with our study, Di Stadio et al. [22] reviewed 35 articles on MS and found that nearly $37 \%$ of MS patients suffered from vertigo and $71 \%$ of them showed altered cVEMPs. A significant percentage (35\%) of the patients with altered VEMPs had a normal MRI. They stated that central vestibular pathways were involved in MS demyelination, mostly in the early stage of the disease, while the peripheral vestibular system was mainly affected in the late stage of MS.

Aidar and Suzuki [25] assessed the presence and absence of symptoms (hearing loss, tinnitus, ear fullness, imbalance, and sudden deafness) in MS patients and compared them with cVEMP results. There was no statistically significant difference (agreeing with our results). They stated that even though non-significant, the group with the presence of symptoms presented a higher number of absent responses (35\%), indicating a trend that might be better assessed with a larger study group.

However, Güven et al. [19] found that cVEMP abnormalities were more frequent in patients with vestibular symptoms than in those without, and more in those with brainstem symptoms than in those without.

In the current study, cerebellar symptoms were more common than brainstem symptoms. The majority of those with combined cerebellar and brainstem symptoms had abnormal cVEMP, and the majority of those with combined cerebellar and brainstem symptoms had a higher percentage of abnormal oVEMP than those without any cerebellar or brainstem symptoms.

Gazioglu and Boz [18] found that there was no statistically significant correlation between the clinical brainstem and VEMP abnormalities. However, MS patients showed a high frequency of abnormality in VEMP tests, especially in oVEMP tests, which suggests that VEMP tests may be useful as an adjunct test in the evaluation of brainstem dysfunction in MS patients.

\section{cVEMP and oVEMP findings v. lesions on MRI}

In the current study, MS patients with a range of lesions on MRI showed comparable cVEMPs, with no statistically significant differences among them. Regarding cVEMPs, MS patients with and without brainstem lesions on MRI showed comparable cVEMP results.

Oh et al. [26] found abnormal cVEMPs in 31-70\% of patients with definite MS. Alpini et al. [27] found abnormal cVEMPs that indicated brainstem dysfunction in $4 \mathrm{MS}$ patients (10\%) with normal MRI and no specific clinical signs. Abnormal results of VEMP in patients with MS 
implicate a lesion of the brainstem, despite normal MRI and/or neurological examination [28]. Versino et al. [29]; Bandini et al. [30]; and Colebatch [31] also found that delayed cVEMPs responses were the most frequent abnormality but showed little correlation with radiological findings, which is in agreement with our results.

Regarding oVEMP, MS patients with brainstem lesions on MRI had a statistically significant greater percentage of latency delay than patients without brainstem lesions on MRI, and compared to MS patients with cerebellar lesions on MRI and compared to MS patients with "other" lesions than brainstem and cerebellar on MRI.

In comparison, Hamed et al. [32] found that oVEMP mean latencies of $\mathrm{N} 1$ and $\mathrm{P} 1$, and cVEMP mean latencies of P13 and N23, were significantly prolonged in the MS group. There were $14 / 30$ (46.7\%) of their MS patients who had brainstem lesions confirmed by MRI. They found that the oVEMP test had higher sensitivity than cVEMP in predicting brainstem lesions.

Results of the current study were statistically significant in just a few aspects of the analysis, mainly in the latency of cVEMP and oVEMP, but only on one side (left side for cVEMP, and right side for oVEMP). However, the distribution of the side of latency delay (whether right or left or bilateral) was not related to the presence or absence of brainstem involvement on MRI in either CVEMP or oVEMP. This suggests the need for further research in this field.

The present study revealed that $14 / 40$ (35\%) of MS patients had abnormality in both cVEMP and oVEMP reflecting lesions in the descending and ascending brainstem pathways. In MS patients, there was no statistically significant difference in the distribution of combined VEMP results - whether combined abnormality in both oVEMP and cVEMP, or only cVEMP was abnormal, or only oVEMP was abnormal, or both oVEMP and cVEMP were normal - and the presence or absence of vertigo, other brainstem symptoms, or brainstem lesions on MRI. In other words, demyelination affects brainstem pathways before symptoms or radiological findings appear, and hence VEMPs might be useful in the early detection of brainstem involvement in MS patients.

However, in the present study, further comparisons of MS patients with vertigo but without brainstem lesions on MRI showed that only $1 / 13$ (8\%) had cVEMP amplitude asymmetry and only 2 had delayed latency - i.e., 3/13 (23\%) had abnormal cVEMP, compared to $10 \%$ in the study of Oh et al. [26].

Regarding oVEMPs, MS patients with vertigo but without brainstem lesions on MRI showed statistically significant delayed Rt N1 and P1 latencies and greater Rt oVEMP rectified amplitude asymmetry than the controls. oVEMP was abnormal in $9 / 13(69 \%)$ including latency delay in $5 / 13(38 \%)$, asymmetry in $2 / 13(15 \%)$, and asymmetry and latency delay in $2 / 13(15 \%)$. This suggests that cVEMP and oVEMP results could be abnormal despite no MRI brainstem sign yet emerging, and might be used as an early measure to assess MS effects on the brainstem, especially when the oVEMP is more affected.
In comparison, Crnošija et al. [33] found that there was a significant correlation between prolonged latencies and/or absent VEMP response and the presence of pontine and medulla oblongata lesions. These differences were evident when they looked at VEMP changes depending on the side (left or right) of the lesion. No differences were observed when they analyzed oVEMP and cVEMP separately. Crnošija et al. [33] found that the VEMP score - the sum of four graded scores derived from the evaluation of oVEMP and CVEMP in both ears (the four grades were $0=$ normal, $1=$ increased latency with normal amplitude and morphology of major potentials, $2=$ decrease in amplitude or altered morphology of major potentials, and 3 = absence of a major potential) - was significantly higher in MS patients with clinical involvement of the brainstem compared with patients without clinical brainstem involvement. They concluded that the VEMP score is a valuable tool in evaluation of brainstem involvement in patients with early MS. This emphasises the use of both cVEMP and oVEMP in assessment of brainstem involvement in MS.

Although MRI is considered to be the single most sensitive test for MS, it is recognized that it cannot detect all lesions in MS patients [34]. Although MS patients do not always show brainstem or cerebellar lesions on imaging studies, vertigo and imbalance mostly arise from structural or functional involvement of the vestibular system. Patients with lesions involving the VOR and VSR pathways may show various degrees of functional impairment [27].

Abnormal results of both types of VEMP in patients with MS implicate lesions of the brainstem, despite normal MRI and/or neurological examination $[35,36]$. Tutar et al. [17] concluded that VEMPs are useful for the evaluation of central vestibulopathies. VEMP testing can diagnose brainstem lesions in RRMS patients quickly, easily, and safely without pain, even when MRI shows no brainstem involvement. VEMP testing is an electrophysiological test that is able to detect early-stage pathologies of the vestibular system.

Sürmeli et al. [37] found that there was no cVEMP response in $31.5 \%$ of patients with MS who had no central vestibular involvement with MRI and who had no subjective vestibular system symptoms. In addition, patients with MS had prolonged P1 and N1 latencies and decreased P1-N1 peak-to-peak amplitudes. They stated that cVEMP can be used for subclinical evaluation in patients with MS without obvious central vestibular system involvement according to MRI.

\section{cVEMP and oVEMP findings $v$. SVV test findings}

In the present study, only 4/40 MS patients (10\%) showed an abnormal SVV result. There were $2 / 4$ of those with abnormal SVV who showed abnormal cVEMP and 3/4 showed abnormal oVEMP, while only $1 / 4$ showed abnormal combined cVEMP and oVEMP. In comparison with our results, Versino et al. [29] found that there was no correlation between the occurrence of abnormalities in VEMP and SVV abnormalities. 


\section{Age of patient and duration of MS}

Neither the age of an MS patient or the duration of MS was correlated to either DHI score, SVV, or cVEMP or oVEMP result. In comparison, Atteya et al. [38] concluded from their study that the risk of falling according to the BBS and BSS assessment increases in older patients, patients with higher EDSS scores, and those with increased duration of illness.

\section{EDSS scores in MS}

In the present study, EDSS scores of MS patients were all less than 4.5, and not correlated to either DHI score, SVV, or cVEMP or oVEMP results.

Güven et al. [19] found in their study of MS patients that there was no relation between disease duration or attack in the previous year and EDSS score or VEMP abnormalities. This agrees with our results. But Crnošija et al. [32] found that the VEMP score correlates well with disease duration and the overall disability of the MS patient as measured by EDSS (all their patients' EDSS scores were <5.5). Gazioglu and $\mathrm{Boz}$ [18] found that correlations with clinical or MRI evidence of brainstem involvement were not significant, but they found that both ocular $(p<0.05)$ and cervical VEMP latencies $(p<0.01)$ were significantly correlated with EDSS (their patients' EDSS scores were $2.6 \pm 2$ ). They stated that these results appear to indicate the possibility of asymptomatic or pre-radiological involvement of the vestibulo-collic or VOR pathways in MS patients.

\section{Conclusions}

1) cVEMP abnormality was found in $37.5 \%$ of $\mathrm{MS}$ patients, which reflected vestibulo-spinal reflex pathology, and oVEMP abnormality was found in $67.5 \%$, which reflected vestibulo-ocular reflex pathology.

2) Although MS patients with and without vertigo showed comparable cVEMP and oVEMP asymmetry results, MS patients with vertigo but without brainstem lesions on MRI showed statistically significant oVEMP latency delay and increased amplitude asymmetry compared to the controls. This suggests that oVEMP can be used as an early measure to assess brainstem effects even when there are no radiological brainstem signs.

3) MS patients with brainstem lesions on MRI had statistically significant oVEMP latency delays compared to patients with cerebellar or "other" lesions on MRI.

4) EDSS scores of MS, and duration of MS, were not correlated to either DHI scores or CVEMP or oVEMP results.

\section{Recommendations}

We recommend the use of cervical and ocular VEMPs in assessment of the VSR and VOR respectively (i.e. the ascending and descending brainstem pathways) in MS patients, especially for detection of early brainstem involvement before brainstem findings appear radiologically in MRI, even in the absence of vertigo symptoms.

\section{References}

1. Colebatch JG, Halmagyi GM. Vestibular evoked potentials in human neck muscles before and after unilateral vestibular deafferentation. Neurology, 1992; 42(8): 1635-6.

2. Colebatch JG, Halmagyi GM, Skuse NF. Myogenic potentials generated by a click-evoked vestibulocollic reflex. J Neurol Neurosurg Psychiatry, 1994; 57(2): 190-7.

3. Curthoys IS. A critical review of the neurophysiological evidence underlying clinical vestibular testing using sound, vibration and galvanic stimuli. Clin Neurophysiol, 2010; 121(2): 132-44.

4. Todd N P, Cousins R, Lee, CS. Ocular vestibular evoked myogenic potentials (OVEMPs) produced by air- and bone-conducted sound. Clin Neurophysiol, 2007; 118(2): 381-90.

5. Oh SY, Kim JS, Lee JM, Shin BS, Hwang SB, Kwak KC. Ocular vestibular evoked myogenic potentials induced by air-conducted sound in patients with acute brainstem lesions. Clin Neurophysiol, 2013; 124(4): 770-8.

6. Oh SY, Kim JS, Yang TH, Shin BS, Jeong SK. Cervical and ocular vestibular-evoked myogenic potentials in vestibular neuritis comparison between air and bone-conducted stimulation. J Neurol, 2013; 260(8): 2102-9.

7. Iwasaki S, McGarvie LA, Halmagyi GM, Burgess AM, Kim J, Colebatch JG. Head taps evoke a crossed vestibulo-ocular reflex. Neurology, 2007; 68(15): 1227-9.

8. Rosengren SM, Nogajiski JH, Cremer PD. Delayed vestibular evoked response to the eyes and neck in a patient with an isolated brainstem lesion. Clin Neurophysiol, 2007; 118: 2112-16.

9. Kim HJ, Lee SH, Park JH, Choi JY, Kim JS. Isolated vestibular nuclear infarction: report of two cases and review of the literature. J Neurol, 2014; 261(1): 121-9.
10. Olek MJ, Dawson DM. Multiple sclerosis and other inflammatory demyelinating diseases of the central nervous system. In: Bradley WG, Daroff RB, Fenichel GM, Jankovic J (eds) Neurology in Clinical Practice. 4th edn. Butterworth Heinemann, Philadelphia, 2004; 4: 1631-64.

11. Milo R, Miller A. Revised diagnostic criteria of multiple sclerosis. Autoimmun Rev, 2014; 13(4-5): 518-24.

12. Murofushi T, Kaga K. VEMP: Vestibular Evoked Myogenic Potential. Its basics and clinical applications. Springer, Tokyo, 2009, p. 101-9.

13. Alsanosi A. Adaptation of the dizziness handicap inventory for use in the Arab population. Neurosciences, 2012; 17(2): 139-44.

14. Jacobson GP, Newman CW. The development of the dizziness handicap inventory. Arch Otolaryngol Head Neck Surg, 1990; 116(1): 424-7.

15. Soliman S. Speech discrimination audiometry using Arabic phonetically balanced words. Ain Shams Med J, 1976; 27: 27-30.

16. Soliman S, Fathalla A, Shehata W. Development of the Arabic Staggered Spondaic Words (SSW) test. Proceedings of the 8th Annual Ain Shams Congress, 1985; 2: 1220-46.

17. Tutar B, Berkiten G, Saltürk Z, Başkadem Yılmazer A, Emir C, Ekincioğlu E. Evaluation of vestibular system using c-VEMP and o-VEMP in patients with relapsing-remitting multiple sclerosis. Tr-ENT, 2019; 29(3): 119-25

18. Gazioglu S, Boz C. Ocular and cervical vestibular evoked myogenic potentials in multiple sclerosis patients. Clin Neurophysiol, 2012; 123(9): 1872-9.

19. Güven H, Bayır Ö, Aytaç E, Özdek A, Çomoğlu SS, Korkmaz H. Vestibular-evoked myogenic potentials, clinical evaluation, and imaging findings in multiple sclerosis. Neurol Sci, 2014; 35: 221-26. 
20. Koura R, Hussein M. Vestibular-evoked myogenic potential: an easy neurophysiological tool for evaluating brain stem involvement in multiple sclerosis. Egypt J Otolaryngol, 2018; 34: 144-48.

21. Somasundaram AC, Gandhirajan D, Avathvadi VS, Kesavamurthy B, Ranganathan LN, Pamidimukkala V. Predicting falls in multiple sclerosis: do electrophysiological measures have a better predictive accuracy compared to clinical measures? Mult Scler Relat Disord, 2018; 20:199-203.

22. Rosengren SM, Nogajiski JH, Cremer PD. Delayed vestibular evoked response to the eyes and neck in a patient with an isolated brainstem lesion. Clin Neurophysiol, 2007; 118: 2112-16.

23. Kim HJ, Lee JH, Kim JS. Ocular vestibular evoked myogenic potentials to head tap and cervical vestibular evoked myogenic potentials to air-conducted sounds in isolated internuclear ophthalmoplegia. Clin Neurophysiol, 2014; 125(5): 1042-7.

24. Di Stadio A, Dipietro L, Ralli M, Greco A, Ricci G, Bernitsas E. The role of vestibular evoked myogenic potentials in multiple sclerosis-related vertigo. A systematic review of the literature. Mult Scler Relat Disord, 2019; 28: 159-64.

25. Aidar RC, Suzuki FA. Vestibular evoked myogenic potential: new perspectives in multiple sclerosis. Rev Bras Otorrinolaringol, 2005; 71(1): 48-54.

26. Oh SY, Kim HJ, Kim JS. Vestibular-evoked myogenic potentials in central vestibular disorders. J Neurol, 2016; 263(2): 210-20.

27. Alpini D, Pugnetti L, Caputo D, Cornelio F, Capobianco S, Cesarani A. Vestibular evoked myogenic potentials in multiple sclerosis: clinical and imaging correlations. Mult Scler, 2004; 10: 316-21.

28. Eleftheriadou A, Deftereos SN, Zarikas V, Panagopoulos G, Sfetsos S, Karageorgiou CL. The diagnostic value of earlier and later components of vestibular evoked myogenic potentials (VEMP) in multiple sclerosis. J Vestib Res, 2009; 19(1-2): 59-66.
29. Versino M, Colnaghi S, Callieco R, Bergamaschi R, Romani A, Cosi V. Vestibular evoked myogenic potentials in multiple sclerosis patients. Clin Neurophysiol, 2002; 113(9): 1464-9.

30. Bandini F, Beronio A, Ghiglione, Solaro C, Parodi RC, Mazzella $\mathrm{L}$. The diagnostic value of vestibular evoked myogenic potentials in multiple sclerosis. J Neurol, 2004; 251(5): 617-21.

31. Colebatch JG. Vestibular evoked myogenic potentials in multiple sclerosis. Clin Neurophysiol, 2012; 123(9): 1693-4.

32. Hamed AA, Beshr AE, Behairy RM, Eladawy II. Vestibular evoked myogenic potential in multiple sclerosis (MS). IJMA, 2020; 2(3): 547-53.

33. Crnošija L, Skorić MK, Gabelić T, Adamec I, Habek M. Vestibular evoked myogenic potentials and MRI in early multiple sclerosis: validation of the VEMP score. J Neurol Sci, 2017; 372: 28-32.

34. Gabelic T, Krbot M, Šefer A, Išgum V, Adamec I, Habek M. Ocular and cervical vestibular evoked myogenic potentials in patients with multiple sclerosis. J Clin Neurophysiol, 2013; 30(1): 86-91.

35. Leocani L, Rovaris M, Boneschi FM, et al. Multimodal evoked potentials to assess the evolution of multiple sclerosis: a longitudinal study. J Neurol Neurosurg Psychiatry, 2006; 77: 1030-5.

36. Invernizzi P, Bertolasi L, Bianchi MR, Turatti M, Gajofatto A, Benedetti MD. Prognostic value of multimodal evoked potentials in multiple sclerosis: the EP score. J Neurol, 2011; 258: 1933-9.

37. Sürmeli R, Sürmeli M, Günay G, Yalçın AD, Şahin Yılmaz AA, Kulalı F. The role of vestibular evoked myogenic potential and the video head impulse test in patients with multiple sclerosis without radiologic findings. Neurol Sci Neurophysiol, 2020; 37: 170-5.

38. Atteya A, Elwishy A, Kishk N, Ismail RS, Badawy R. Assessment of postural balance in multiple sclerosis patients. ESNPN, 2019; 55: 7 . 